\title{
Alternative algorithms for syndromic diseases management to minimize the misuse / over-use of antibiotic in non-viral Sexually Transmitted Infections
}

Subash Chandra Sonkar ${ }^{1,2}$, Rekha Bharti ${ }^{1}$, Mashook Ali² Geetika Arora², Pratima Mittal ${ }^{1 \#}$, Daman Saluja ${ }^{2 \#}$

1. Department of Obstetrics \& Gynecology Vardhman Mahavir Medical College and Safdarjung Hospital, New Delhi 110029, India

2. Medical Biotechnology Laboratory, Dr. B.R. Ambedkar Center for Biomedical Research, University of Delhi, Delhi 110007, India

Introduction : Syndromic approach is a simple and affordable approach for STI management in low resource countries. However, due to lack of confirmation and accuracy, risk of over-use/misuse of antibiotic is very high. In this study, we propose a more specific and accurate algorithm compared to current algorithm used for syndromic case management with laboratory outcome.

Methods : The study is divided into two categories; Category I- Based on existing NACO-NACP guidelines symptoms of infection were scored and patient were treated, Category II, in alternative syndromic approach all the samples were tested by PCR for $C$. trachomatis (CT), N. gonorrhoeae (NG) and T. vaginalis (TV) before giving treatment.

Results: For category I, amongst 646 syndromically infected women, only 46 (7.13\%) tested positive by PCR assay for one the pathogen while rest of $600(92.87 \%)$ were negative for these three pathogens. The total estimated percentage of the overuse and misuse of antibiotics is $\mathbf{8 4 . 5 2 \%}$ and $\mathbf{1 5 . 4 8 \%}$ respectively. Correct and complete treatment based on laboratory outcome compared to NACP was 42/46 (91.30\%). The estimated overuse of antibiotics prevalence of Azithromycin and Cifixime was (55.49\%), combination of Dixycilin, Cefixime, Metrodizonole (30.95\%) and combination of Dixycilin, Cifixime, Metrodizonole, Azithromycin (13.55\%). For category II, wherein patients were treated using alternative syndromic approach and compared with PCR diagnostics, 243/319(76.15\%) subjects were infected with either one of the pathogen (NG/TV/CT), whereas 76/319(23.82\%) women were negative for any of these three pathogens. Amongst 243 infected patients, 99(40.74\%) were infected with single pathogen while 144/243 (59.2\%) was co-infected. Prevalence of TV, NG \& CT was 13.13\%, 65.65\% and 21.21\% respectively. Co-infection with CT $+N G$ was highest, 51.38\% (74/144) followed by infection with all the three pathogens (30\%). Co-infection with CT + TV was $9.72 \%$ and $N G+T V$ was $9.03 \%$. The estimated overuse of antibiotics was only $24 \%$.

Conclusions : The proposed alternative algorithms can reduce the rate of misuse / over-use of antibiotics from $92 \%$ to $24 \%$.

Keywords: India, NACO, alternative algorithms, STI, PCR, antibiotics, C. trachomatis, N. gonorrhoea, T.vaginalis.
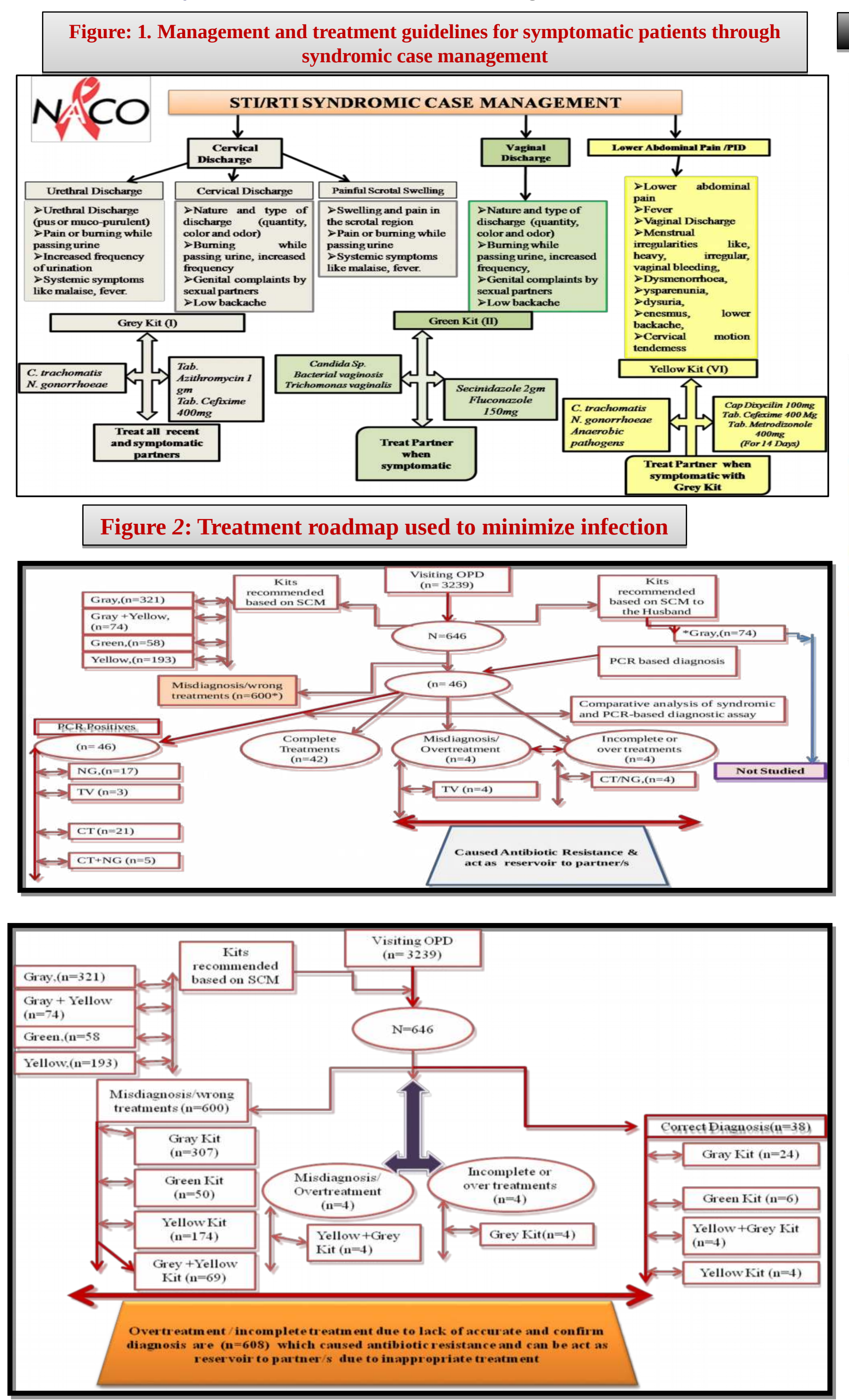

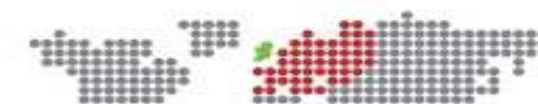

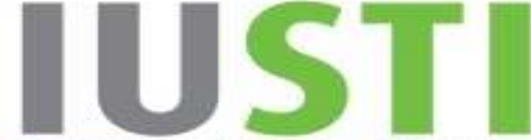

2018 WORLD + EUROPEAN CONGRESS $27^{\text {TH }}-30^{\text {TH }}$ JUNE, DUBLIN IRELAND

\begin{tabular}{|c|c|c|c|c|}
\hline S.N. & Microorganisms & Gene & References & Primers Sequences \\
\hline $\mathbf{1}$ & C. trachomatis & gyrA & Patel et al., & C2 5'TGATGCTAGGGACGGATTAAAACC3' \\
\cline { 5 - 5 } & & & 2009 & C5 5'TTCCCTAAATTATGCGGTGGAA3' \\
\hline $\mathbf{2}$ & N. gonorrhoeae & Orf1 & $\begin{array}{c}\text { Chaudhary et. } \\
\text { al. 2002 }\end{array}$ & F 5'CAACTATTCCCATTGCGA3' \\
\cline { 5 - 5 } & & & R 5'GTTATACAGCTTCGCCTGAA3' \\
\hline 3 & T. vaginalis & $p f o B$ & $\begin{array}{c}\text { Sonkar et al., } \\
2016\end{array}$ & F 5'CAAAGTCAACATGGCTATGAT3' \\
\cline { 4 - 5 } & & & R 5' GAAGACCTGTGTGGATGGATGT 3' \\
\hline
\end{tabular}

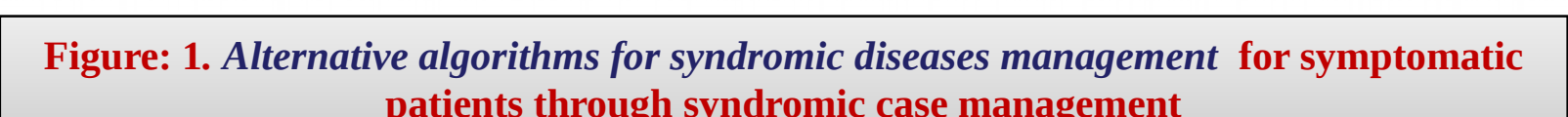
patients through syndromic case management
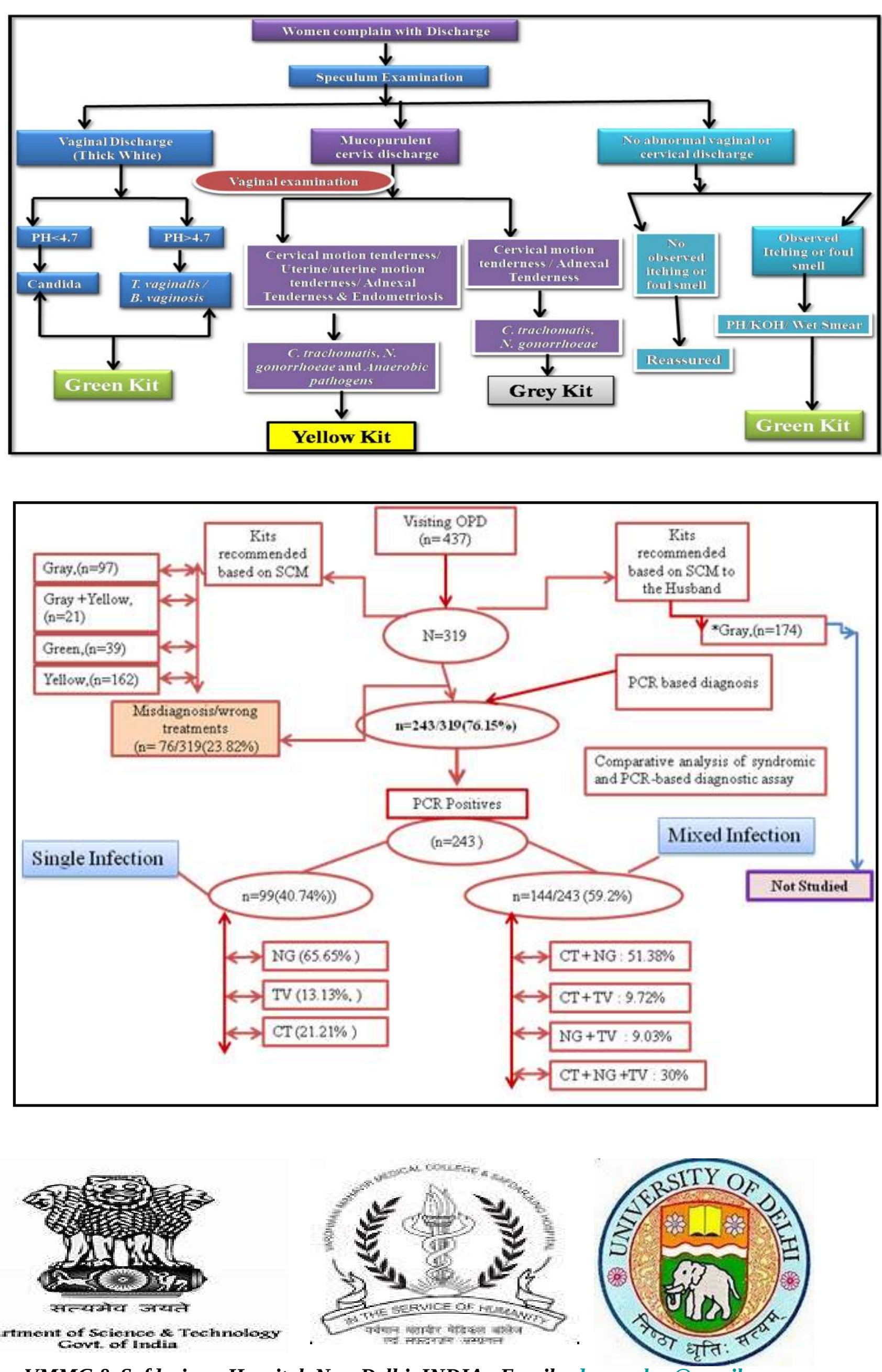

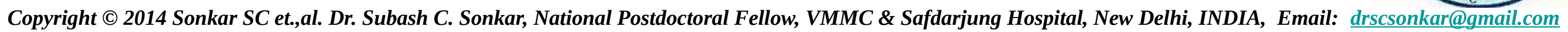

